\title{
The potential of offering HIV-related services in an optometry environment
}

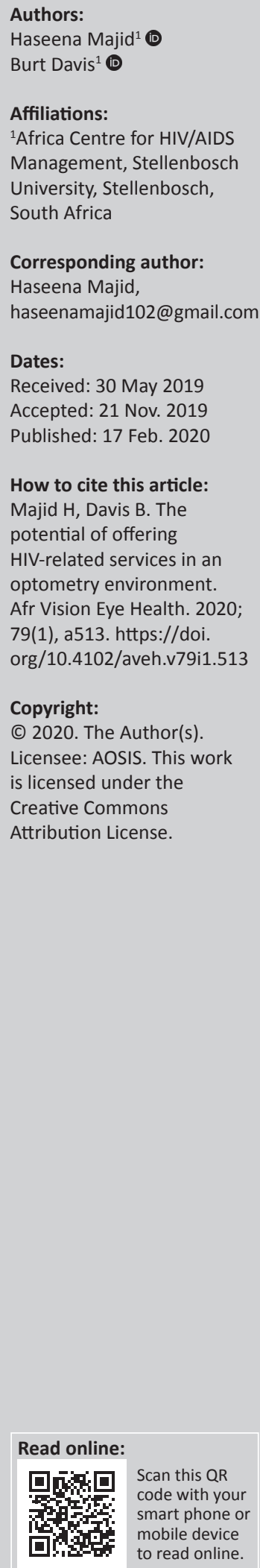

Background: Despite the successes of testing campaigns in South Africa, many people still do not know their human immunodeficiency virus (HIV) status, and the number of new infections remains high. Delayed access to testing is a contributing factor in this regard. Utilising less conventional health settings to test for HIV, such as optometry practices, could help increase the opportunities to test for HIV.

Aim: To investigate the potential of the optometry environment as a possible contributor to capacity building for HIV testing and counselling services.

Setting: Three optometry practices in Pietermaritzburg, South Africa.

Methods: A survey design approach was used with participants $(n=30)$ completing a researcher-designed 16-item questionnaire.

Results: The results showed that the optometry environment was generally perceived as conducive for possible HIV testing, as the majority of participants felt that testing for HIV at an optometry practice would be more convenient $(90 \% ; n=27)$, compared to testing at a clinic, with a clear preference for testing for HIV at an optometry practice as opposed to a clinic $(93 \% ; n=27)$.

Conclusion: The results of this study seem to illustrate a willingness within the optometry patient population to be receptive to the possibility of screening for HIV. However, while optometry falls within the ambit of primary health services for vision and eye health, the profession is yet to produce a guideline document detailing the exact scope of practitioners with regard to systemic health screenings. As such, HIV screening is not specified at present.

Keywords: HIV/AIDS; testing; screening; counselling; optometry; voluntary counselling testing; VCT; HIV testing and counselling, HCT; HIV testing services; HTS.

\section{Introduction}

According to Venter et al., ${ }^{1} 66.5 \%$ of South Africans had a human immunodeficiency virus (HIV) test and knew their status in 2014, with the percentage of people knowing their HIV status increasing from $50 \%$ to $66.5 \%$ between 2008 and 2014 . Avert ${ }^{2}$ puts this figure at $86 \%$ of people being aware of their HIV status. This means that South Africa is almost meeting the first of the 90-90-90 targets of the Joint United Nations Programme on HIV and AIDS (UNAIDS) to be reached by 2020 , namely, that $90 \%$ of all people living with HIV will know their HIV status. ${ }^{3}$

In spite of the successes of HIV testing with many people being aware of their HIV status, the number of people living with the disease in South Africa continues to be much higher than the global average. ${ }^{4}$ About 19.4 million people were living with HIV and AIDS in Eastern and Southern Africa in 2017, with South Africa carrying the maximum burden of the infection rate. ${ }^{5}$ An estimated 7.1 million people in South Africa have HIV or AIDS (the highest in the world), with 270000 new HIV cases and 110000 AIDS-related deaths reported during 2016. ${ }^{6}$ Reasons for the high number of people living with HIV in South Africa have been associated with socioeconomic factors and the unequal and inequitable access to medical care, especially for people in the underdeveloped parts of the country. ${ }^{4}$ In this regard, delayed access to testing remains a significant contributor to the spread of HIV. ${ }^{7}$ Compounding these is the fact that the rate of testing uptake amongst males in South Africa, particularly amongst young males, appears to be substantially lower compared to their female counterparts. ${ }^{8,9,10}$ This means that more should be done to increase the HIV testing uptake in South Africa. One way to do this, as Venter et al. ${ }^{1}$ remarked, is to consider new HIV testing approaches such as self-testing as an alternative approach to HIV testing, and another possibility could be to expand our traditional view of a HIV testing service provider. 
This paper investigates if patients presenting for optometry services perceive that optometrists could play a role in increasing the number of people knowing their HIV status in South Africa by offering their patients the opportunity to test for HIV at their practices as part of their eye care routine. The global response to HIV, sparked by its rapid growth, especially on the African continent, has forced countries and global institutions, such as the World Health Organization (WHO), United Nations and the World Bank, to explore and develop multi-sectoral approaches aimed at capacitating HIV status awareness and mitigating the spread of the infection. ${ }^{11}$ In a South African context, one of the main objectives of the South African National AIDS Council (SANAC) is to strengthen the multi-sectoral response to $\mathrm{HIV}^{12}$ In this sense, optometrists - as non-conventional HIV testing service providers - can play an important role by offering more convenient opportunities to test for HIV.

To the best of our knowledge, the research presented here is the first of its kind exploring the possible contribution that optometry environments can make to address public health challenges such as dealing with the HIV pandemic.

\section{An overview of the current HIV testing and counselling approaches in South Africa}

The Joint United Nations Programme on HIV and AIDS or UNAIDS $^{13}$ defines HIV counselling and testing (HCT) as the process of providing counselling to an individual to enable him/her to make an informed choice about being tested for HIV. Human immunodeficiency virus testing and counselling in South Africa has had different iterations over the years and is mainly concerned with a shift in focus about how the process is rolled out. HIV testing and counselling consists of two main approaches, namely, voluntary counselling testing (VCT) or client-initiated counselling and testing (CICT) and provider-initiated HIV counselling and testing (PICT) ${ }^{14}$ The main difference between VCT and PICT is that VCT is based on a person approaching a service provided for HIV testing, whereas PICT is the so-called provider-initiated approach, where people are approached to do an HIV test even if they had not sought it as part of the reasons for wanting health services in the first place. ${ }^{15,16}$ Voluntary counselling testing services have been available in South Africa since $2000^{16}$ and currently, the name HIV testing services (HTS) is preferred to HCT. According to the National HIV Testing Services: Policy $2016,17,18$ the name change from HCT to HTS was necessitated to encompass the full range of services that should be provided together with HIV testing. These services include pre- and post-test counselling; linkage to appropriate HIV prevention, treatment, care and other clinical support services; and coordination with laboratory services to support quality assurance and the delivery of correct results. All forms of HTS, when implemented, should use a validated testing algorithm from the WHO consisting of the ' $5 C^{\prime}$ 's': consent, confidentiality, counselling, correct tests results and connection, which is the linkage to prevention care and treatment. ${ }^{1}$
Different policy documents and guidelines are available in South Africa regarding HCT. Amongst others, the National HIV Testing Services: Policy 2016 and the National HIV Counselling and Testing Policy Guidelines (2010) ${ }^{14,17}$ can be used. Aspects of the HCT protocol can also be found in the South African National Strategic Plan for HIV, sexually transmitted infections and tuberculosis (2017-2022). ${ }^{12}$

One of the first 'types' of non-clinical HIV testing programmes, 'Know Your Status', was started in 2005 at a private university in North Carolina in the United States as a student initiative to increase the uptake of HCT among institutions of higher learning. ${ }^{19}$ This programme entailed free testing and counselling to students on campuses for easy access. ${ }^{19}$ In South Africa, non-clinical responses that have shown a positive contribution have included extensive HIV campaigns by state and private entities. These campaigns have advocated for, among others, routine screening for HIV, which has been at the forefront of many successful HIV-related responses. For example, since the launch of an HCT campaign in 2010 for public servants by the Department of Public Service and Administration in partnership with the National Department of Health and SANAC, 18 million people have been tested. ${ }^{20}$

\section{Why test for HIV at the optometrist?}

Testing for HIV in an optometry environment may be particularly advantageous for the following reasons. Firstly, optometry in South Africa and other countries the world over is a primary healthcare service, which aims to diagnose, treat and appropriately refer patients within the primary healthcare system and for specialised care. ${ }^{21}$ A primary healthcare provider often is an entry point for patients into the healthcare system. Optometrists are enabled to diagnose, examine and treat conditions related to the eye while having a greater understanding and knowledge of other risk factors, epidemics and conditions that are the major causes of disease and death within the areas/country they practice in. ${ }^{22}$ Optometrists are thus considered primary healthcare practitioners and are required to have a broader understanding of all primary healthcare conditions. Therefore, as a primary healthcare provider, the extension of optometry services to include HIV screening amongst other systemic health screenings should be relatively easy to do. Currently, however, the South African Optometric Association (SAOA) does not have clinical guidelines for which optometrists can respond to the epidemiological demands of the South African population, including guidelines with regard to systemic health screenings. As such, HIV screening is not yet allowed within this environment. At present, the practice of optometry in South Africa is largely guided by the American Optometric Association guidelines. ${ }^{23}$ Secondly, there are various nongovernment organisations and philanthropic initiatives, using volunteer optometrists and undergraduate students, that offer outreach eye health services to rural communities who are not always able to access eye care services easily 
(Wimble K 2017, personal communication, September 07). These platforms could be used to improve access to HIV testing. As stated, delayed access to testing is a significant contributor to the spread of HIV.7 Although the accessibility to optometrists by patients utilising public health facilities still remains largely poor in the South African context, ${ }^{24}$ the increased scope of practice for optometrists as primary healthcare givers since the end of apartheid has helped to increase public sector access to optometry practices and eye health services in recent years. ${ }^{25}$ There are approximately 3200 registered optometrists and close to 3200 practices in South Africa. ${ }^{26}$ Currently, optometrists in South Africa are not trained to provide testing services. ${ }^{27}$ Thirdly, expanding the scope of optometry practice to include HCT could increase the HIV-related knowledge levels of optometrists. This could empower them to more effectively detect ocular changes of their patients related to HIV / AIDS. ${ }^{28}$

Testing for HIV in an optometry environment may increase the number of people who know their HIV status and improve the range of services that optometrists can provide. The purpose of this study was to explore if patients presenting to optometry practices perceive this environment as a potential contributor to capacity building for HCT services.

\section{Research methods and design}

A survey was conducted using a 16-item questionnaire that explored the following aspects regarding optometry practices: (1) accessibility as HIV testing sites; (2) possible platform for increasing HIV status awareness; (3) potential positive provider to mitigate the rate of HIV infections; and (4) an alternative avenue for patients, to afford them linkage to testing, care and appropriate referrals.

A purposive sampling approach ${ }^{29}$ was used and included participants who had utilised optometry services. This was deemed necessary as people accessing optometry services were expected to be in a better position to give insights pertaining to the potential of the optometry environment as contributors to capacity building towards HCT, compared to a group who have not visited an optometrist before. The study included both male and female optometry patients aged 18-49 years. These inclusion criteria were based on the fact that the highest rate of HIV infection was found in the 15-49 age group, with no gender predilection. ${ }^{30}$ Only those patients who could read and comprehend written material in English were included.

Participants were recruited at three optometry practices in Pietermaritzburg, South Africa, namely, the East Street, Longmarket Street and Scottsville branches of the Majid Optometrist stores. These stores were chosen because of their diverse geographical patient bases. Participants (after completing their optometry appointment or in the waiting room) were randomly approached by the researcher and were requested to participate in the survey after the nature of the study was explained to them. Those who agreed were asked to sign a consent form prior to completing the survey questionnaire onsite. All questions were in English and questionnaires were collected immediately afterwards. In spite of it being time-consuming owing to the explanation process necessary to capture the interest of potential participants, a benefit of administering the questionnaire in this setting was that it often caught the interest of other patients in the waiting area, which made the process of recruiting participants easier.

The first three items of the 16-item questionnaire measured demographic variables (age, gender and occupation). The next two items were related to the respondent's HIV testing history and the time since the last test. These were aimed at assessing the participants' familiarity with and willingness to engage in voluntary HIV screening. Refer to Table 1 for the complete item list. The questionnaire was developed and pretested by the researchers for comprehension and understanding. No concerns were forthcoming. The data were analysed using descriptive statistics.

\section{Ethical considerations}

Ethical clearance for this study was obtained from the Stellenbosch University Research Ethics Committee (ethical clearance number: SU-HSD-003195). Informed consent was obtained from all the participants.

Ethical principles considered were whether the participants had to make a voluntary and conscious decision free from coercion about their participation in the research, while the research design made sure that the confidentiality and anonymity of participants were guaranteed. Ethical clearance for this study was obtained from the university. Informed consent was explained to all participants. The consent form detailed the purpose of the study, the procedure, the potential risk and discomforts, the potential benefits to the participants and society, confirmation and confidentiality, the right to participate voluntarily, the right to decline participation, the right to withdraw following participation and the right to researcher and supervisor contact information. Participants were also provided with an information leaflet offering them additional information related to the study (e.g. details of a psychologist and general practitioner, which they could use in case they required more information about or assistance with any HIV-related matter).

\section{Results}

A total of 30 participants were included in the study. This was deemed a representative sample of the population, given that an average of $60-70$ patients visited these three optometry practices on a monthly basis. Time and financial constraints also did not allow for a bigger sample to be included. In total, 14 participants $(80 \%)$ fell into the 25- to 49 -year age group, with 10 male participants (33\%) and 20 female participants (67\%) participating in the study. The occupation demographic indicated a diverse population, including private and state employees, students, unemployed and self-employed people, and those with no specific job portfolio. 
Twenty eight (93\%) participants reported that they had previously tested for HIV, while two participants (7\%) had not been tested before. Of those who reported having been tested for HIV previously, 16 (53\%) were tested more than 2 years earlier and $12(40 \%)$ within a 2 -year period.

As Table 1 shows, the majority of participants were mostly positive about optometry practices being a potential contributor to capacity building for HCT services. When asked if they would feel comfortable with their optometrist testing them for HIV, participants were asked to mention the motivation behind their responses. Three participants indicated that it is because they trusted the skills and the ability of the optometrists to counsel and refer them appropriately. Others said that they were comfortable because of confidentiality and privacy $(n=7)$. When asked whether they would prefer to be tested for HIV at their optometrist compared to having it done at a clinic or hospital, participants were also asked to mention the motivation behind their responses. The most prominent reasons cited by participants for opting to test for HIV at an optometry site compared to a clinic or hospital was that it was less timeconsuming $(n=11)$ and offered more privacy $(n=14)$.

\section{Discussion}

This exploratory study aimed to assess if patients perceived an optometry environment as a suitable site to increase linkage to care related to HIV testing, and if optometrists in their role as primary healthcare givers could play a role in reducing the burden of this disease in the communities within which they operate.

The respondent population varied in age and included a high number of female participants. The majority of participants had prior experience of HIV counselling and testing at more conventional sites. In the context of this study, this finding may be considered encouraging, as it may have enabled participants to give a more informed opinion about using optometry sites to test for HIV as opposed to those who may not have tested before.

The first main finding was that the optometry environment was generally perceived as conducive for HIV testing. As the results showed, the majority of participants said that HIV testing at optometry practices would be more convenient and practical as well as safer, compared to testing at a clinic or hospital. There was also a clear preference to test for HIV at an optometry practice as opposed to a clinic or hospital. The second main finding was that participants generally perceived optometrists as adequate and reliable to manage the testing and counselling process. The results showed that the majority of participants indicated they would feel comfortable if their optometrist tested them for HIV, while most participants felt they could trust their optometrist to conduct HIV testing.

A possible explanation as to why most participants indicated that optometry practices are conducive for possible HIV testing can be found in the motivations given for preferring to test at an optometrist as opposed to a clinic or hospital. These reasons included that testing in an optometry environment would be more private and less timeconsuming, compared to a clinic or hospital, and are indicative of South Africa's health system, which at this time is in an ailing state. The current infrastructure is barely sustainable. The budgetary crisis at the national and provincial levels has translated into a human resource crisis within many primary healthcare facilities. The growing population, with a diminishing health infrastructure, has resulted in poor service delivery at health facilities, long waiting queues and increasing frustration felt by both healthcare providers and patients alike. Barriers to the uptake of services include lack of access to service, long waiting times and low staff numbers. ${ }^{31}$ The time-saving opportunity for patients and the re-routing of a needed service to a less conventional setting may yield a dual benefit to the patient and the facility. People who desire to be screened for HIV would no longer be deterred by long queues and time wasting, and the burden on clinics and health facilities would be reduced. Priority can then be given to patients in need of therapeutic, surgical and emergency medical intervention in the time it would have taken for the HIV screening to be conducted.

A likely reason about why most participants generally perceived optometrists as adequate and reliable to manage

TABLE 1: Items included to explore if patients presenting to optometry practices perceive this environment as a potential contributor to capacity building for human immunodeficiency virus testing and counselling services.

\begin{tabular}{|c|c|c|}
\hline Items & Frequency $(n)$ & $\begin{array}{l}\text { Percentage of participants } \\
\text { in agreement }\end{array}$ \\
\hline Would HIV testing in an optometry environment be more convenient for you than testing at a clinic? & 27 & 90 \\
\hline Would HIV testing in an optometry environment be more practical for you than testing at a clinic? & 28 & 93 \\
\hline Would HIV testing in an optometry environment be safer for you than testing at a clinic? & 28 & 93 \\
\hline Would HIV testing in an optometry environment be less of a burden if included as part of an ocular exam? & 25 & 83 \\
\hline Would you trust your optometrist to test you for HIV? & 26 & 87 \\
\hline Would you be comfortable if your optometrist tested you for HIV? & 28 & 93 \\
\hline If you wanted to test for HIV, would you prefer to test for HIV at an optometrist as opposed to at a clinic or hospital? & 27 & 90 \\
\hline Do you feel comfortable disclosing your medication list to your optometrist? & 25 & 83 \\
\hline Do you follow through on healthcare recommendations or referrals made by your optometrist? & 26 & 87 \\
\hline Do you think people would test for HIV at an optometrist if they were given the opportunity? & 29 & 97 \\
\hline Would you advise someone to test for HIV at their optometrist? & 28 & 93 \\
\hline
\end{tabular}


the HCT process may relate to the vital role optometrists often play in managing the burden of diseases such as diabetes and hypertension (which, similar to HIV, needs to be chronically managed). For example, the basic eye test that an optometrist conducts can involve, if required, investigative techniques such as taking blood pressure. ${ }^{27}$ Some of the participants may have been exposed to such procedures in an optometry environment. This, in turn, may have influenced their perceptions that optometrists can manage the HIV testing process effectively as well.

The current study was not without its limitations. Firstly, this research was a small-scale study, which possibly limited the generalisability of the results. Secondly, the study was restricted as it was limited to English as the language medium. The study may have benefitted from including isiZulu speakers. However, budget limitations did not allow for translations or the use of a translator (the principal investigator was not fluent in isi-Zulu). Thirdly, the predominantly dichotomous design of the questionnaire design was restrictive. However, a lengthy questionnaire would not have been logistically possible, as it would have impeded on optometry appointments scheduled for the day.

Based on the findings of this study, the following recommendations are made. Firstly, training institutions should strengthen the public health component of the optometry syllabus such that it capacitates optometrists sufficiently to provide sound knowledge and support to people within the communities they serve. Secondly, SAOA should be urged to make available optometry clinical guidelines that are aligned with the epidemiological needs of the South African population. These guidelines should be specific about the optometrist's role in broader health promotion and address issues on the possibility of offering HIV screening services. Thirdly, the scope of practice for optometrists and the Health Professions Council of South Africa (HPCSA) regulations should be revised to clearly indicate the competency and capacity of eye health clinicians practicing in South Africa. Fourthly, if allowed to conduct HIV screening services at optometry practices, it is recommended that such services should be incentivised by state or private funders. Incentivising this service should encourage optometrists to expand their service offerings to increase their output to the patients and communities they serve to extend to public health concerns, early identification of risk factors and signs of HIV infection, and to make appropriate and quick referrals.

\section{Conclusion}

Involving less conventional stakeholders in the fight against HIV/AIDS - such as the optometrists - can potentially contribute to limiting the spread of the virus. Optometry practices in the public and private sectors need to be promoted as sites for linkage to broader healthcare and not be limited to eye testing only. Such actions would also help to create a platform for a multidisciplinary approach to healthcare, which in terms of HIV/AIDS will adhere to the
UNAIDS initiative highlighting the importance of the integration of this disease into broader healthcare systems. ${ }^{4}$

\section{Acknowledgements}

The authors would like to acknowledge the Africa Centre for HIV/AIDS Management, Stellenbosch based on the thesis submitted in 2017 - Stellenbosch University.

\section{Competing interests}

The authors have declared that no competing interests exist.

\section{Authors' contributions}

H.M. is the primary researcher and the first author, while B.D. supervised and edited the article and is the second author.

\section{Funding information}

This study was self-funded by the authors.

\section{Data availability statement}

Data sharing is not applicable to this article.

\section{Disclaimer}

The views and opinions expressed in this article are those of the researchers only and do not necessarily reflect the official policy or position of any affiliated agency of the authors.

\section{References}

1. Venter F, Majam M, Jankelowitz L, et al. South African HIV self-testing policy and guidance considerations. S Afr HIV Med. 2017;18(1):9. https://doi.org/10.4102/ sajhivmed.v18i1.775

2. Avert. HIV/AIDS in South Africa [homepage on the Internet]. [cited 2018 Mar 14]. Available from: https://www.avert.org/professionals/hiv-around-world/subsaharan-africa/south-africa

3. UNAIDS. 90-90-90-An ambitious treatment target to help end the AIDS epidemic [homepage on the Internet]. [cited 2018 Mar 14]. Available from: http://www. unaids.org/en/resources/documents/2017/90-90-90

4. UNAIDS. Global report: UNAIDS report on the global AIDS epidemic 2013 [homepage on the Internet]. [cited 2018 Mar 14]. Available from: https://doi. org/JC2502/1/E

5. UNAIDS. Fact sheet World AIDS Day 2018 [homepage on the Internet]. UNAIDS [cited 2018 Mar 14]. Available from: http://www.unaids.org/sites/default/files/ media_asset/UNAIDS_FactSheet_en.pdf

6. UNAIDS. Country, South Africa. [homepage on the Internet]. [cited 2018 Mar 14]. Available from: http://www.unaids.org/en/regionscountries/countries/southafrica

7. Shisana O, Rehle T, Simbayi LC, et al. South African National HIV prevalence, incidence and behaviour survey. Cape Town: HSRC Press, 2012; p. 194.

8. Johnson LF. HIV testing in South Africa. Successes and challenges [homepage on the Internet]. [cited 2018 Mar 14]. Available from: http://sacemaquarterly.com/ wp-content/uploads/2015/09/Leigh_HIV-testing_article-3.pdf

9. Peltzer K, Matseke G. Determinants of HIV testing among young people age 18-24 in South Africa. J Afr Health Sci. 2013;13(4):1012-1020. https://doi.org/10.4314/ ahs.v13i4.22

10. Orr N, Hajiyiannis $H$, Maers $L$, et al. Development of a national campaign addressing South African men's fear about HIV counselling and testing and antiretroviral treatment. J AIDS. 2017;74(Suppl 1):S69-S73. https://doi.org/ 10.1097/QAI.0000000000001204

11. Mahlangu P, Vearey J, Thomas L, Goudge J. Implementing a multi-sectoral response to HIV: A case study of AIDS councils in the Mpumalanga Province, South Africa. Global Health Action. 2017;10(1):1387411. https://doi.org/10.1080 /16549716.2017.1387411

12. National Department of Health (NDoH). South African National Strategic Plan for HIV, STIs and TB 2017-2022 [homepage on the Internet]. [cited 2019 Nov 13]. Available from: https://sanac.org.za/download-the-full-version-of-the-nationalstrategic-plan-for-hiv-tb-and-stis-2017-2022-2/ 
13. UNAIDS. Fact sheet 2015 [homepage on the Internet]. UNAIDS. [cited 2018 Mar 14]. Available from: https://doi.org/http://www.unaids.org/sites/default/ files/media_asset/20150901_FactSheet_2015_en.pdf

14. National Department of Health (NDoH). National HIV counselling and testing policy guidelines (2010) [homepage on the Internet]. [cited 2019 Nov 13]. Available from: https://aidsfree.usaid.gov/sites/default/files/hts_policy_south-africa.pdf

15. Lovelife. HCT \& youth: Issues, challenges, and lessons learned [homepage on the Internet]. [cited 2018 Mar 14]. Available from: https://lovelife.org.za/en/ YouthHCT2010.pdf

16. Makhunga-Ramfolo N, Chidarikire T, Farirai T, Matji R. Provider-initiated counselling and testing (PICT): An overview. S Afr J HIV Med. 2011;12(2):6, 8, 10, 11. https://doi.org/10.4102/sajhivmed.v12i2.190

17. National Department of Health (NDoH). National HIV testing services: Policy 2016 [homepage on the Internet]. Pretoria. [cited 2019 Nov 13]. Available from: https://sahivsoc.org/Files/HTS\%20Policy\%2028\%20July\%20final\%20copy.pdf

18. NACOSA. HCT becomes HTS [homepage on the Internet]. [cited 2018 Mar 14] Available from: https://www.nacosa.org.za/2016/04/04/hct-becomes-hts/

19. Milligan C, Cuneo CN, Rutstein SE, Hicks C. Know your status results from a novel, students-run HIV testing initiative on college campuses. AIDS Educ Prev. 2014;26(4):317-327. https://doi.org/10.1521/aeap.2014.26.4.317

20. South African Government. HIV Counselling and Testing (HCT) campaign [homepage on the Internet]. [cited 2018 Mar 14]. Available from: https://www. gov.za/about-government/government-programmes/hiv-counseling-and-testinghct-campaign

21. WHO Regional Office for Africa. Core competencies for the eye health workforce in the WHO African Region [homepage on the Internet]. Brazzaville: WHO Regional Office for Africa; 2019 [cited 2020 Feb 12]. Available from: https://www. iapb.org/wp-content/uploads/Core-Competencies-for-Eye-HWF-in-WHO-AFRO Region.pdf
22. Kleinstein RN, Lehman HF. Primary health care-the role of optometry. Clin Exp Optom. 1976;59(2):57-62. https://doi.org/10.1111/j.1444-0938.1976.tb01864.x

23. Padilla MA, Di Stefano AF. A snapshot of optometry around the world. Rev Optom. 2009;146(6):55-58.

24. Maake ME, Moodley VR. An evaluation of the public sector optometric service provided within the health districts in KwaZulu-Natal, South Africa. Afr Vision Eye Health. 2018;77(1), a407. https://doi.org/10.4102/aveh.v77i1.407

25. SAOA. Submission in response to Green Paper - National Health Insurance in South Africa [homepage on the Internet]. Johannesburg: SAOA; 2011 [cited 2020 Jan 27]. Available from: https://www.mm3admin.co.za/documents/docmanager/ C97E4C72-D696-4E42-B491-D49D93B964CC/00021686.pdf

26. SAOA. Submission to the Health Market Inquiry 2015. SAOA Oral Presentation at Public Hearings [homepage on the internet]. [cited 2020 Feb 06]. Available from: https://docplayer.net/30130298-Health-market-inquiry-oral-presentation-publichearings.html

27. HPCSA. Guidelines for the Professional Board of Optometry and Dispensing Opticians [homepage on the Internet]. [cited 2019 Nov 13]. Available from:
https://www.hpcsa.co.za/Uploads/ODO_2019/BAsic\%20eye $\% 20$ exam $\% 20$ https://www.
guidelines.pdf

28. Govender P, Hansraj R, Visser L. Ocular manifestations of HIV/AIDS: A literature review (Part 1). S Afr Optom. 2010;69(4):193-199. https://doi.org/10.4102/aveh. review (Part

29. Christensen LB, Johnson BR, Turner LA. Research methods, design and analysis. 11th ed. Boston, NJ: Pearson Higher Ed, 2014; p. 159.

30. Erasmus M. UNAIDS South Africa [homepage on the Internet]. [cited 2016 Apr 13]. Available from: http://www.unaids.org/en/regionscountries/countries/southafrica

31. Maphumulo WT, Bhengu BR. Challenges of quality improvement in the healthcare of South Africa post-apartheid: A critical review. Curationis. 2019;42(1):a1901. https://doi.org/10.4102/curationis.v42i1.1901 